\section{Large-Scale Purification of a Stable Form of Recombinant Tobacco Etch Virus Protease}

BioTechniques 30:544-554 (March 2001)

\begin{abstract}
Tobacco etch virus NIa proteinase (NIaPro) has become the enzyme of choice for removing tags and fusion domains from recom binant proteins in vitro. We have designed a mutant NIa-Pro that resists autoproteolytic inactivation and present an efficient method for producing large amounts of this enzyme that is highly pure, active, and stable over time. Histidine-tagged forms of both wildtype and mutant NIa-Pro were overexpressed in $\mathrm{E}$. coli under conditions in which greater than $95 \%$ of the protease was in the insoluble fraction after cell lysis. An inclusion body preparation followed by denaturing purification over a single affinity column and protein renaturation yields greater than $12.5 \mathrm{mg}$ enzyme per liter of bacterial cell culture. NIaPro purified according to this protocol has been used for quantitative removal of fusion domains from a variety of proteins prepared for crystallization and biochemical analysis.
\end{abstract}

\section{INTRODUCTION}

Advances in recombinant protein technology over the past decade have led to the routine use of affinity tags to aid protein purification for applications including protein engineering and structural biology. Proteases are frequently used to remove these tags following purification, yielding native protein for subsequent applications. Factor Xa, commonly used for this purpose, is relatively inefficient, nonsequence specific, and cannot be recombinantly expressed. In contrast, tobacco etch virus NIa proteinase (NIa-Pro) recognizes a specific heptapeptide sequence, E-X-X-Y-X$\mathrm{Q} \downarrow \mathrm{S} / \mathrm{G}$, and is active under a wide range of conditions and in the presence of various protease inhibitors $(3,4,6,8,9)$.

In nature, NIa-Pro is the 27-kDa proteolytic portion of the $49-\mathrm{kDa}$ NIa polypeptide found as an aggregate with the 54-kDa NIb polypeptide in nuclear inclusion bodies in infected plant cells $(2,7)$. Purification of NIa-Pro in large quantity has proved difficult because of the limited solubility of the protein. Inclusion bodies purified from infected plant tissue with subsequent separation of the 49- and 54-kDa polypeptides did not yield significant amounts of active NIa-Pro $(5,7)$. Native purification of a histidine-tagged recombinant NIa-Pro from $E$. coli similarly produced low quantities of protease because the majority of the recombinant protein resides in inclusion bodies (7). An additional problem with NIa-Pro is that it contains an internal self-cleavage site that, when proteolyzed, produces a truncated protease with significantly reduced activity (7). Autoproteolysis during preparation and long-term storage thus reduces the yield of fully active protease.

To address these issues, a single amino acid change that inhibits autoproteolysis without affecting substrate cleavage activity, Ser219Asn (S219N), was introduced at the self-cleavage site within NIa-Pro. Furthermore, a protocol was developed for the denaturing purification and efficient renaturation of active NIa-Pro from inclusion bodies in $E$. coli. NIa-Pro purified using this protocol has been utilized to process a variety of fusion-tagged proteins that have been subsequently used for biochemical and crystallographic studies $(1,10,11)$.

\section{MATERIALS AND METHODS}

\section{Cloning}

A wild-type NIa-Pro gene was generated by PCR using pTL-5495 (ATCC, Manassas, VA, USA) as the template. The $5^{\prime}$ primer 5TEVP1, 5'-CATCAGCGGGCCATGGCTGAAAGCTTGTTTAAG- $3^{\prime}$, changes the $\mathrm{N}$ terminus of NIa-Pro from the wild-type Gly-GluSer to Met-Ala-Glu-Ser and contains an $N c o$ I restriction site for cloning. The $3^{\prime}$ primer 3TEVH1, 5'-CTGATGCACG GATCCTCATTAATGGTGATGGTGATGGTGCAATTGCGAGTAGATTCACTG-3', encodes a Leu-His6 tag and a BamHI restriction site for cloning. The mutant NIa-Pro gene was generated by sequential PCRs. For the first reaction, pTL-5495 was used as the template with primers 5TEVP1 and TEVPSN, 5'-GAGTTGAGTTGCTTCTTTGACT GGCTGAAAGGGTTCTTCAGGTTTGTTCATGAAAACTTTGTGGC-3', to introduce the S219N mutation at the internal self-cleavage site. The resultant PCR product mixture was used as the template in a second PCR using the $5^{\prime}$ primer 5TEVP1 and the $3^{\prime}$ primer 3TEVH1. PCR products were ligated into the pET15b expression vector (Novagen, Madison, WI, USA) using the $N c o I$ and $B$ a $m \mathrm{HI}$ sites transformed into E. coli $\mathrm{DH} 5 \alpha^{\mathrm{TM}}$ (Life Technologies, Rockville, MD, USA) competent cells, and ampicillin-resistant colonies were selected. The resulting plasmids, pTPWT and pTPSN, encoding polypeptides with molecular weights of 28.6 $\mathrm{kDa}$, were sequenced for accuracy and then transformed into BL21 (DE3) (Novagen) competent cells for expression.

\section{Protease Expression and Purification}

NIa-Pro was expressed in BL21 (DE3) cells grown at $37^{\circ} \mathrm{C}$ in Luria Broth supplemented with $100 \mu \mathrm{M}$ ampicillin until cultures reached an absorbance $(600 \mathrm{~nm})$ of approximately 1.0. Expression was induced by adding $400 \mu \mathrm{M}$ isopropyl- $\beta$-D-thiogalactoside (IPTG) followed by vigorous aeration at $37^{\circ} \mathrm{C}$ for $4-5 \mathrm{~h}$. Cell pellets from each liter of culture were harvested by centrifugation, resuspended in $25 \mathrm{~mL}$ buffer containing $50 \mathrm{mM}$ Tris- $\mathrm{HCl}, \mathrm{pH}$ 8.0 , and $300 \mathrm{mM} \mathrm{NaCl}$, and stored at $-80^{\circ} \mathrm{C}$. Cell lysis and native purification of NIa-Pro were performed as described (7) using nickel affinity chromatography (Ni-NTA Superflow; Qiagen, Valencia, CA, USA), except $10 \%$ glycerol, $300 \mathrm{mM} \mathrm{NaCl}$, and $5 \mathrm{mM} 2-$ mercaptoethanol were included in all buffers, and the Ni-NTA column was washed with buffer containing $10 \mathrm{mM}$ imidizole and eluted with buffer containing $400 \mathrm{mM}$ imidizole. For inclusion body purification, cell suspensions were thawed in cool water, and the buffer was adjusted to a final concentration of $500 \mu \mathrm{g} / \mathrm{mL}$ lysozyme (Sigma, St. Louis, MO, USA), $200 \mu \mathrm{g} / \mathrm{mL}$ DNase I (Roche Molecular Biochemicals, Indianapolis, IN, USA), $50 \mu \mathrm{g} / \mathrm{mL}$ PMSF, $10 \mu \mathrm{g} / \mathrm{mL}$ leupeptin (Roche Molecular Biochemicals), $20 \mathrm{mM}$ 


\section{Short Technical Reports}

Table 1. Purification Yields from Native and Denaturing NIa-Pro Protocols ${ }^{a}$

\begin{tabular}{|c|c|c|c|c|c|c|}
\hline Nla-Pro & Method & $n^{\mathbf{b}}$ & $\begin{array}{c}\text { Total Protein In } \\
\text { Ni-NTA Load (mg) }\end{array}$ & $\begin{array}{l}\text { Total Ni-NTA Pure } \\
\text { Protein (mg) }\end{array}$ & $\begin{array}{l}\text { Active Nla-Proc } \\
\text { (mg) }\end{array}$ & $\%$ yieldd \\
\hline \multirow[t]{2}{*}{ TPWT } & Native & 1 & 977 & 4.08 & $<0.41$ & $<0.04$ \\
\hline & Denaturing & 5 & 80 & $32.25 \pm 4.12$ & $9.07 \pm 2.90$ & 0.86 \\
\hline \multirow[t]{2}{*}{ TPSN } & Native & 1 & 946 & 3.67 & $<0.37$ & $<0.04$ \\
\hline & Denaturing & 7 & 81 & $31.79 \pm 5.07$ & $9.87 \pm 2.21$ & 0.96 \\
\hline \multicolumn{7}{|c|}{ aYields are reported as milligrams protein per liter cell culture. } \\
\hline \multicolumn{7}{|c|}{${ }^{b} n$ is the number of independent preparations. } \\
\hline \multicolumn{7}{|c|}{$\begin{array}{l}\text { CActive Nla-Pro was not assayed for the native preparations; milligrams of active Nla-Pro are estimated to be less than } 10 \% \\
\text { of the total Ni-NTA-pure protein. Data reported for the denaturing preparations reflect the yield from the initial dialysis of the } \\
\text { Ni-NTA eluate. }\end{array}$} \\
\hline
\end{tabular}

$\mathrm{MgSO}_{4}$, and $2 \mathrm{mM} \mathrm{CaCl}_{2}$. Cell suspensions were incubated for $30 \mathrm{~min}$ with agitation at $4{ }^{\circ} \mathrm{C}$ and then lysed by three freeze-thaw cycles. Triton ${ }^{\circledR} \mathrm{X}-100$ was added to a final concentration of $1 \%$, and the samples were vortex mixed for $1 \mathrm{~min}$. The inclusion bodies were recovered by centrifugation for $20 \mathrm{~min}$ at $10000 \times g$. Pellets were stored at $-80^{\circ} \mathrm{C}$.

Chromatography under denaturing conditions was performed at $4{ }^{\circ} \mathrm{C}$ using $10 \mathrm{~mL}$ Ni-NTA Superflow resin for each liter of cell culture. The column was equilibrated with 10 column volumes (cv) equilibration buffer containing $6 \mathrm{M}$ urea, $100 \mathrm{mM} \mathrm{NaH} \mathrm{PO}_{4}$, and $10 \mathrm{mM}$ Tris- $\mathrm{HCl}, \mathrm{pH}$ 8.0. Inclusion body pellets were resuspended in buffer containing $6 \mathrm{M}$ guanidine- $\mathrm{HCl}, 100$ $\mathrm{mM} \mathrm{NaH}_{2} \mathrm{PO}_{4}$, and $10 \mathrm{mM}$ Tris- $\mathrm{HCl}$, $\mathrm{pH} 8.0$, and incubated in a $65^{\circ} \mathrm{C}$ bath to dissolve the inclusion bodies. Samples were centrifuged for $20 \mathrm{~min}$ at $15000 \times$ $g$, and the supernatant was loaded onto the column by gravity flow. The column was washed with $4 \mathrm{cv}$ equilibration buffer and then $6 \mathrm{cv}$ wash buffer containing $6 \mathrm{M}$ urea, $100 \mathrm{mM}$ $\mathrm{NaH}_{2} \mathrm{PO}_{4}$, and $10 \mathrm{mM}$ Tris- $\mathrm{HCl}, \mathrm{pH}$ 6.3. To elute the protein, a buffer containing $6 \mathrm{M}$ urea, $100 \mathrm{mM} \mathrm{NaH} \mathrm{PO}_{4}$, and $10 \mathrm{mM}$ Tris- $\mathrm{HCl}, \mathrm{pH} 4.5$, was applied to the column and one $0.3-\mathrm{cv}$ fraction was collected. Flow was stopped for a 5-min incubation, then was resumed, and four additional 1-cv fractions were collected. Fractions containing NIa-Pro, as determined by
SDS-PAGE, were pooled, adjusted to $\mathrm{pH} 8.5$ with $10 \mathrm{~N} \mathrm{NaOH}$, and dialyzed for $4-8 \mathrm{~h}$ into storage buffer containing $100 \mathrm{mM}$ Tris- $\mathrm{HCl}, \mathrm{pH} 8.5,500 \mathrm{mM}$ $\mathrm{NaCl}, 50 \%$ glycerol, $5 \mathrm{mM}$ dithiothreitol (DTT), and $0.5 \mathrm{mM}$ EDTA. The supernatant containing active renatured NIa-Pro was separated from precipitated NIa-Pro by centrifugation for 20 $\min$ at $15000 \times \mathrm{g}$, and both were stored at $-80^{\circ} \mathrm{C}$. The precipitated NIa-Pro was redissolved in equilibration buffer and dialyzed into fresh storage buffer to obtain additional pools of active protease.

NIa-Pro preparations were quantified using the Bradford assay (Bio-Rad Laboratories, Hercules, CA, USA) with bovine serum albumin as the standard. NIa-Pro from the native preparation was not assayed for activity due to significant contamination with other proteins. The yield of active enzyme in these samples was estimated to be less than $10 \%$ of the total nickel affinity-purified protein. For the denaturing preparation, the active NIa-Pro yield is reported as milligrams of NIa-Pro obtained from two cycles of renaturation as described.

\section{Activity Assays}

A $17-\mathrm{kDa}$ substrate with the sequence I-E-G-R-P-A-A-E-N-L-Y-F$\mathbf{Q} \downarrow \mathbf{G}-\mathrm{M}-\mathrm{G}-\mathrm{D}-\mathrm{V}-\mathrm{L}-\mathrm{S}$ at the $\mathrm{N}$ terminus contains both a factor Xa cleavage site (underlined sequence with cleavage after R) and a NIa-Pro cleavage site (bold letters with cleavage at the arrow). When cleaved with commercially available TEV protease (Life Technologies), this substrate yields a $15-\mathrm{kDa}$ peptide. Factor Xa (43 kDa) and NIaPro $(28.6 \mathrm{kDa})$ cleavage activities were compared in $30-\mu \mathrm{L}$ reactions containing $250 \mu \mathrm{M}$ substrate, $2.33 \mu \mathrm{M}$ Factor Xa (New England Biolabs, Beverly, MA, USA) or $0.86 \mu \mathrm{M}$ NIa-Pro, and 20 $\mathrm{mM}$ Tris- $\mathrm{HCl}, \mathrm{pH}$ 8.0, $200 \mathrm{mM} \mathrm{NaCl}$, and $2 \mathrm{mM} \mathrm{CaCl}_{2}$. Reactions were incubated at $23^{\circ} \mathrm{C}$ for $6 \mathrm{~h}$. Samples were analyzed by electrophoresis in $15 \%$ SDSPAGE gels and stained with Coomassie ${ }^{\circledR}$ Blue. NIa-Pro activity was assayed in $30-\mu \mathrm{L}$ reactions containing 100,250 , or $500 \mu \mathrm{M}$ substrate, 0.86 $\mu \mathrm{M}$ NIa-Pro, and $50 \mathrm{mM}$ Tris- $\mathrm{HCl}, \mathrm{pH}$ 8.0, $1 \mathrm{mM}$ DTT, and $0.5 \mathrm{mM}$ EDTA. Reactions were incubated at $30^{\circ} \mathrm{C}$ for 1 h. Samples were analyzed by electrophoresis in 15\% SDS-PAGE gels, stained with Coomassie Blue, and the resultant protein bands were quantified using a gel documentation system (Eastman Kodak, Rochester, NY, USA). The net intensities of full-length and cleaved substrate bands were used to calculate a specific activity as picomoles substrate cleaved per femptomole NIa-Pro at each substrate concentration. Self-cleavage activity was assayed under the same buffer conditions in $40-\mu \mathrm{L}$ reactions containing 6.5 $\mu \mathrm{M}$ NIa-Pro and incubated at $4^{\circ} \mathrm{C}$, $-20^{\circ} \mathrm{C}$, and $-80^{\circ} \mathrm{C}$. After $0.5,1,2$, and 5.5 weeks, samples were analyzed by 


\section{Short Technical Reports}

electrophoresis in $15 \%$ SDS-PAGE gels and quantitated as described above. The net intensities of full-length and truncated NIa-Pro bands were used to calculate the percent NIa-Pro

\section{RESULTS}

Following induction of NIa-Pro expression in $E$. coli, native preparations yield minimal quantities of the protease (Figure 1, lane 4 and Table 1) (7). The NIa-Pro detected in high quantity within total cell lysate is concentrated in inclusion bodies, suggesting that virtually all of the enzyme is expressed as insoluble aggregate (Figure 1, lanes 1-3). Expression was explored at a variety of temperatures ranging from $20^{\circ} \mathrm{C}$ to $37^{\circ} \mathrm{C}$; even at low temperatures, which generally favor the soluble expression of proteins, the majority of the NIa-Pro resided in the insoluble fraction. Nickel affinity column purification under decleaved at each time point.

Table 2. NIa-Pro Renaturation Yields ${ }^{\mathrm{a}}$

\begin{tabular}{|lcc|}
\hline \multicolumn{1}{|c|}{ TPWT } & TPSN \\
\hline Ni-pure protein (mg) & $32.25 \pm 4.12$ & $31.79 \pm 5.07$ \\
First renaturationb: & \\
total yield (mg) & $9.07 \pm 2.90$ & $9.87 \pm 2.21$ \\
\% Ni-NTA pure protein renatured & 27.9 & 31.0 \\
Two renaturation cyclesc: & $12.68 \pm 3.25$ & $13.62 \pm 2.49$ \\
total yield (mg) & 39.3 & 42.8 \\
\% Ni-NTA pure protein renatured & \\
aYields reported as milligrams protein per liter cell culture. & \\
bThe first renaturation data are the yields of soluble, active Nla-Pro from the ini- \\
tial dialysis of the Ni-NTA elutions, adjusted to pH 8.5. \\
cData reported for two renaturation cycles are the total yields of soluble, active \\
Nla-Pro from the initial dialysis of the Ni-NTA elutions, adjusted to pH 8.5, plus \\
one subsequent renaturation from the dialysis pellet.
\end{tabular}

naturing conditions enabled recovery of significant amounts of NIa-Pro from the insoluble fraction. Furthermore, this material is of greater purity than that produced under soluble conditions

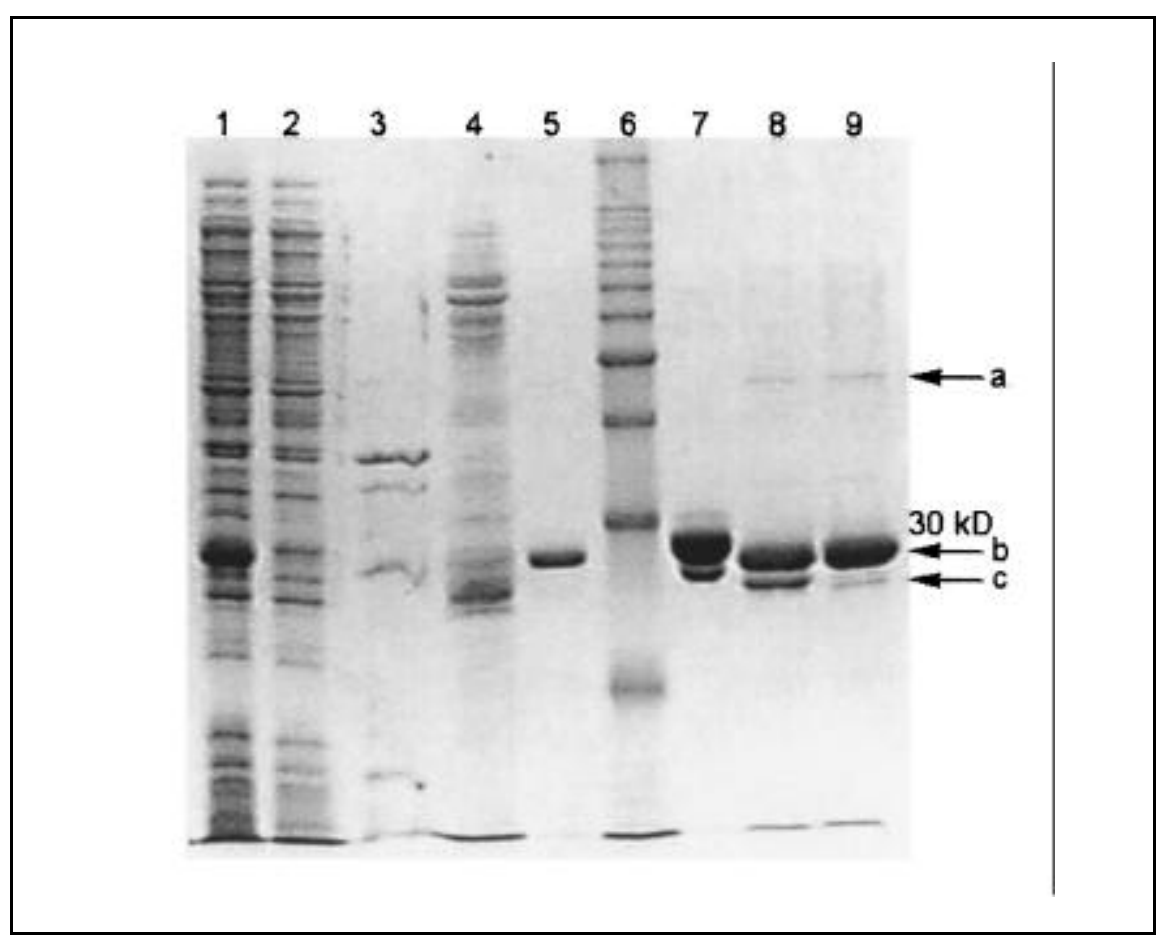

Figure 1. Fifteen percent SDS-PAGE gel of purification samples from native and denaturing preparations of NIa-Pro. Lanes 1-5, TPSN purifications: lane 1, total cellular lysate; lane 2, clarified lysate; lane 3, resuspended inclusion body pellet (in $6 \mathrm{M} \mathrm{GuHCl}$ ); lane 4, concentrated Ni-NTA pure sample from native purification; lane 5, renatured TPSN from denaturing purification. Lane 6 contains a 10-kDa protein ladder (Life Technologies). Lanes 7-9 contain approximately $4.5 \mu \mathrm{g}$ NIa-Pro: lane 7, NIa-Pro control (Life Technologies); lane 8, renatured TPWT from denaturing purification; lane 9, renatured TPSN from denaturing purification. Arrows a-c indicate significant bands: a, the major contaminant in denaturing NIa-Pro preparations; b, full-length NIa-Pro; and c, truncated NIa-Pro produced by self-cleavage activity.
(Figure 1, lanes 4 and 5). In samples containing $4.5 \mu \mathrm{g}$ total protein, a single contaminant (Figure 1, lanes 8 and 9, arrow a) is detected in NIa-Pro from the denaturing protocol, indicating greater than $95 \%$ purity. NIa-Pro purified in this way was renatured by dialysis to remove urea, resulting in approximately $10 \mathrm{mg}$ active wild-type (TPWT) and S219N (TPSN) forms of the enzyme per liter of cell culture (Table 1). A second renaturation of the dialysis pellet yielded additional active enzyme for a total yield of greater than $12.5 \mathrm{mg}$ renatured active NIa-Pro per liter of cell culture (Table 2). Approximately $30 \%$ of the affinity-purified protein was renatured after the first dialysis, and a total

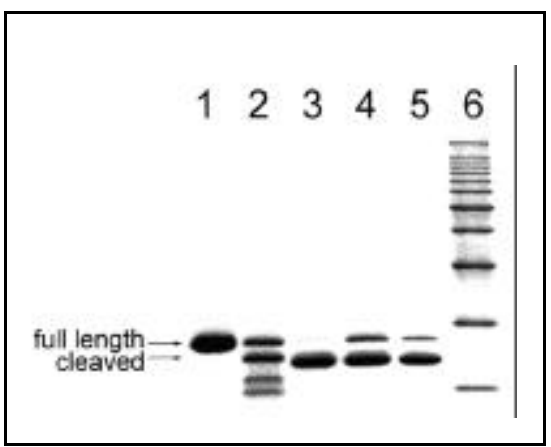

Figure 2. Fifteen percent SDS-PAGE gel of factor Xa and NIa-Pro substrate cleavage reactions. Lane 1 contains full-length substrate. Lanes $2-5$, substrate proteolysis reactions: lane 2 , factor Xa; lane 3, NIa-Pro control; lane 4, TPWT; and lane 5, TPSN. Lane 6 contains a 10-kDa protein ladder. Substrate was incubated for $6 \mathrm{~h}$ at $23^{\circ} \mathrm{C}$ with $2.33 \mu \mathrm{M}$ factor Xa or $0.86 \mu \mathrm{M}$ NIa-Pro. 
of $40 \%$ was renatured after two dialysis cycles (Table 2). The average concentration of renatured preparations was approximately $1.0 \mathrm{mg} / \mathrm{mL}$ with a maximum solubility of $1.5 \mathrm{mg} / \mathrm{mL}$ (data not shown). Average concentrations of samples dialyzed directly out of elution buffer at $\mathrm{pH} 4.5$ were approximately 0.3 $\mathrm{mg} / \mathrm{mL}$ (data not shown), indicating that adjusting to $\mathrm{pH} 8.0-8.5$ is critical for efficient refolding.

Substrate cleavage by NIa-Pro produces a single product, whereas factor $\mathrm{Xa}$ proteolysis yields the desired polypeptide plus two additional degradation products (Figure 2). There also appears to be more unreacted substrate remaining after incubation with factor Xa than with NIa-Pro, despite the use of almost three times as much enzyme in the factor Xa reaction. TPWT and TPSN have specific activities similar to each other and to the commercially available NIaPro at all substrate concentrations tested (Figure 3), demonstrating that refolding does not compromise enzyme activity. Full activity is also further evidence of the purity of these preparations.

Both the commercially available NIa-Pro and purified TPWT contain significantly more truncated enzyme than TPSN in the final preparation (Figure 1, lanes 7-9, arrows b and c). To assess self-cleavage activity, we utilized a C-terminal histidine tag to bind only full-length peptide to the Ni-NTA column. Final TPWT preparations contain approximately $20 \%$ truncated peptide (Figure 4A, $t=0$ ) indicating selfcleavage activity during protease renaturation at $4^{\circ} \mathrm{C}$. Self-cleavage continues during enzyme storage at $4^{\circ} \mathrm{C}$ or $-20^{\circ} \mathrm{C}$ (Figure $4, \mathrm{~A}$ and B), potentially reducing the proportion of fully active enzyme in a NIa-Pro stock over time. The self-cleavage activity of TPWT is similar to that of the control protease at $4^{\circ} \mathrm{C}$ and $-20^{\circ} \mathrm{C}$. In contrast, TPSN exhibits reduced self-cleavage activity at $4^{\circ} \mathrm{C}$ and none at $-20^{\circ} \mathrm{C}$ (Figure $4, \mathrm{~A}$ and B). None of the NIa-Pro samples tested exhibited significant self-proteolysis at $-80^{\circ} \mathrm{C}$ during our 5.5-week study (data not shown).

\section{DISCUSSION}

The high specificity of the NIa-Pro protease for the heptapeptide sequence $\mathbf{E}-\mathrm{X}-\mathrm{X}-\mathbf{Y}-\mathbf{X}-\mathbf{Q} \mathbf{Q}^{\downarrow} \mathbf{S} / \mathbf{G}$ and its activity in the presence of protease inhibitors and under a wide range of conditions make NIa-Pro an ideal tool for quantitative removal of fusion tags from recombinant proteins. We have shown that $E$. coli strains transformed with wild-type, as well as mutant, histidine-tagged NIaPro constructs can be induced to express greater than $95 \%$ of the protease in inclusion bodies (Table 1 and Figure 1). This property was exploited to produce milligram quantities of NIa-Pro using an efficient purification and renaturation protocol. A single denaturing affinity column purification of the NIa-Pro inclusion bodies, followed by renaturation of the purified enzyme yields 10 times as much active NIa-Pro as the soluble preparation (7), allowing greater than $12.5 \mathrm{mg}$ stock preparations of greater than $95 \%$ pure active NIaPro to be prepared per liter of cell culture (Table 2). Improved yields and the ability to denature and renature NIaPro without the loss of activity, as shown by comparison to a commercially available NIa-Pro, might also be exploited for crystallographic and biochemical analysis of this protease.

Within the NIa-Pro self-cleavage site, G-H-K-V-F-M ${ }^{\downarrow}$ S, Ser219 is the only amino acid matching the consensus substrate cleavage site (7). The S219N mutation in TPSN significantly inhibits self-cleavage activity (Figure 3, A and B), allowing for increased yields of full-length NIa-Pro. It also permits long-term storage (at least six weeks) of NIa-Pro stocks at $-20^{\circ} \mathrm{C}$ and shortterm storage (up to six weeks) at $4^{\circ} \mathrm{C}$ without significant autoproteolysis. The mechanism of self-cleavage was not studied, but a S219A mutant exhibited wild-type levels of self-cleavage activity (data not shown). Parks et al. (7) reported significantly less substrate cleavage activity of the truncated form of NIa-Pro compared to the full-length enzyme. We found comparable specific activities for both wild-type and mutant NIa-Pro with our substrate despite the fraction of truncated polypeptide present in the control and wild-type samples (Figure 2). This effect may be concentration or substrate dependent, and activity with other substrates is currently under investigation.

The significantly greater specificity of NIa-Pro over factor Xa makes this protease a superior tool for many protein applications. Development of a rapid and efficient protocol for the ex-

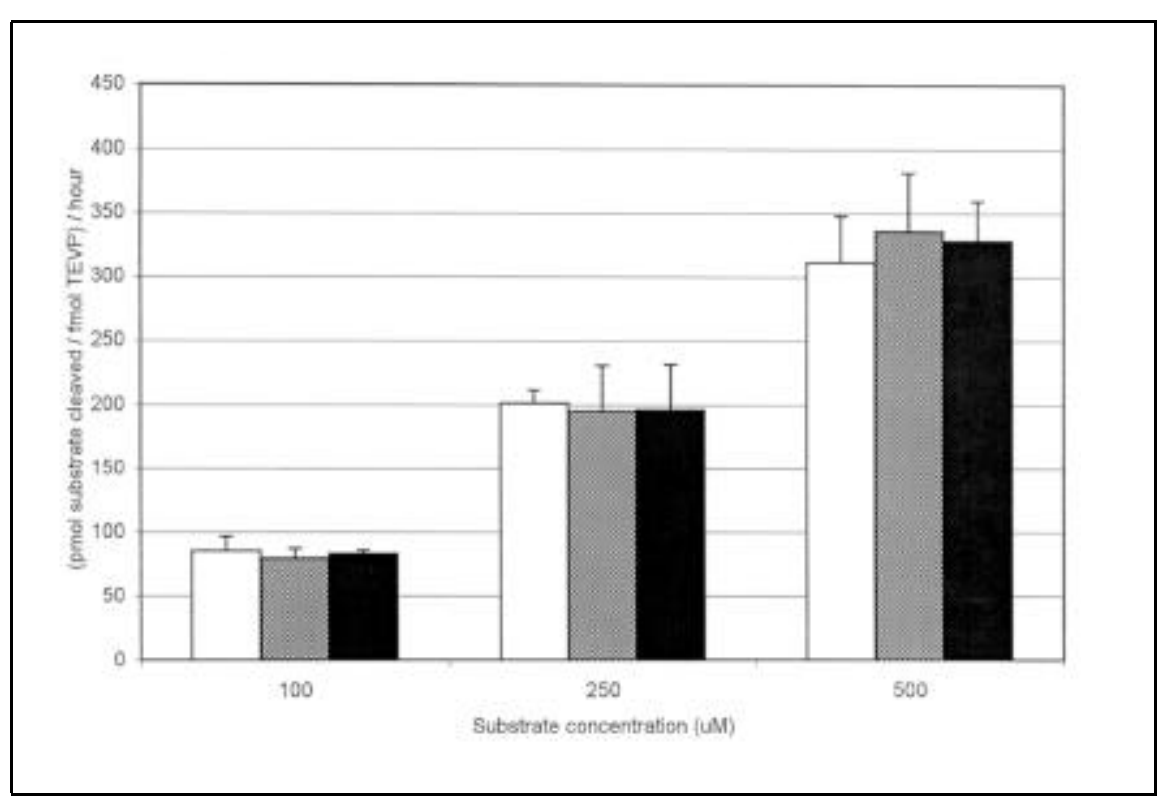

Figure 3. The activity of commercially available NIa-Pro control (white bars, $n=3$ ), TPWT (shaded bars, $n=6$ ), and TPSN (black bars, $n=8$ ) at various substrate concentrations is reported with error bars to reflect the standard deviation. Approximately $0.9 \mu \mathrm{M}$ NIa-Pro was incubated for $1 \mathrm{~h} \mathrm{at}$ $30^{\circ} \mathrm{C}$ with 100,250 , and $500 \mu \mathrm{M}$ substrate. The net intensities of bands on Coomassie blue-stained $15 \%$ SDS-PAGE gels were used to calculate specific activity as the picomoles substrate cleaved per femptomole NIa-Pro in $1 \mathrm{~h}$ at $30^{\circ} \mathrm{C}$. 


\section{Short Technical Reports}

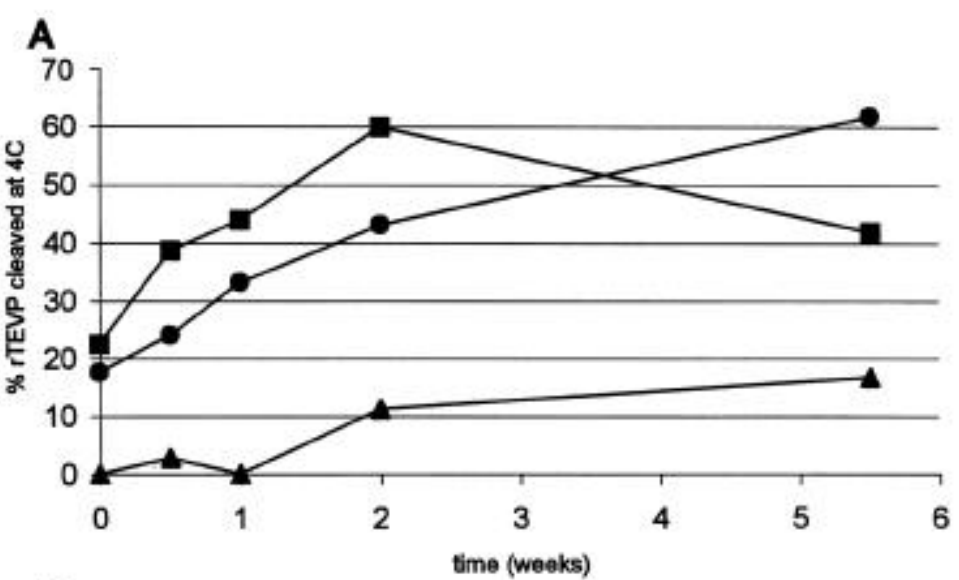

cleavage of affinity tags from expressed proteins. Focus 16:2-5.

10.Purdy, M.D. and M.C. Wiener. 2000. Expression, purification, and initial structural characterization of YadQ, a bacterial homolog of mammalian $\mathrm{ClC}$ chloride channel proteins. FEBS Lett. 466:26-28.

11.Wang, C.R., L. Esser, C.S. Smagula, T.C. Sudhof, and J. Deisenhofer. 1997. Identification, expression, and crystallization of the protease-resistant conserved domain of synapsin I. Protein Sci. 6:2264-2267.

R.T.B. was a Fellow of the Jane Coffin Childs Memorial Fund for Medical Research. Address correspondence to Dr. Jennifer A. Doudna, Howard Hughes Medical Institute, Dept. of Molecular Biophysics and Biochemistry, Yale University, New Haven, CT 06511, USA.e-mail:doudna@

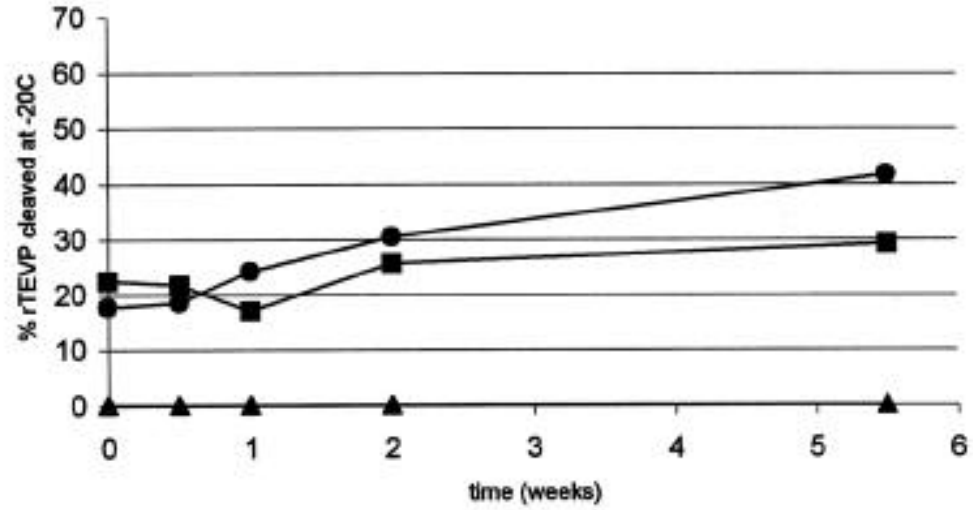
csb.yale. edu

Received 19 July 2000; accepted 29 September 2000.

Louise J. Lucast, Robert T. Batey, and Jennifer A. Doudna Yale University New Haven, CT, USA

pression and purification of milligram quantities of recombinant NIa-Pro should also facilitate the routine use of this protease.

\section{REFERENCES}

1.Batey, R.T., R.P. Rambo, L. Lucast, B. Rha, and J.A. Doudna. 2000. Crystal structure of the ribonucleoprotein core of the signal recognition particle. Science 287:1232-1239.

2.Carrington, J.C. and W.G. Dougherty. 1988. A viral cleavage site cassette: identification of amino acid sequences required for tobacco etch virus polyprotein processing. Proc. Natl. Acad. Sci. USA 85:3391-3395.

3.Dougherty, W.G., J.C. Carrington, S.M. Cary, and T.D. Parks. 1988. Biochemica and mutational analysis of a plant virus polyprotein cleavage site. EMBO J. 7:1281-1287.

4.Dougherty, W.G., S.M. Cary, and T.D. Parks. 1989. Molecular genetic analysis of a plant virus polyprotein cleavage site: a model. Virology 171:356-364.

5.Dougherty, W.G. and E. Hiebert. 1980.
Translation of potyvirus RNA in a rabbit reticulocyte lysate: identification of nuclear inclusion proteins as products of tobacco etch virus RNA translation and cylindrical inclusion protein as a product of the potyvirus genome. Virology 104:174-182.

6.Dougherty, W.G. and T.D. Parks. 1989 Molecular genetic and biochemical evidence for the involvement of the heptapeptide cleavage sequence in determining the reaction profile at two tobacco etch virus cleavage sites in cell-free assays. Virology 172:145-155.

7.Parks, T.D., E.D. Howard, T.J. Wolpert, D.J. Arp, and W.G. Dougherty. 1995. Expression and purification of a recombinant tobacco etch virus NIa proteinase: biochemical analyses of the full-length and a naturally occurring truncated proteinase form. Virology 210:194-201.

8.Parks, T.D., K.K. Leuther, E.D. Howard, S.A. Johnston, and W.G. Dougherty. 1994 Release of proteins and peptides from fusion proteins using a recombinant plant virus proteinase. Anal. Biochem. 216:413-417.

9.Polayes, D.A., A. Goldstein, G. Ward, and A.J.J. Hughes. 1994. TEV protease, recombinant: a site-specific protease for efficient 